Ann. Geophys., 36, 987-998, 2018

https://doi.org/10.5194/angeo-36-987-2018

(C) Author(s) 2018. This work is distributed under

the Creative Commons Attribution 4.0 License.

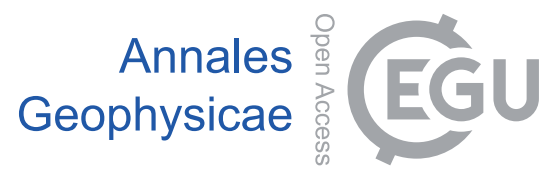

\title{
Ionospheric and thermospheric response to the 27-28 February 2014 geomagnetic storm over north Africa
}

\author{
Khalifa Malki ${ }^{1}$, Aziza Bounhir ${ }^{1}$, Zouhair Benkhaldoun ${ }^{1}$, Jonathan J. Makela ${ }^{2}$, Nicole Vilmer ${ }^{3}$, Daniel J. Fisher ${ }^{2}$, \\ Mohamed Kaab $^{1}$, Khaoula Elbouyahyaoui ${ }^{1}$, Brian J. Harding ${ }^{2}$, Amine Laghriyeb ${ }^{1}$, Ahmed Daassou ${ }^{1}$, and \\ Mohamed Lazrek ${ }^{1}$ \\ ${ }^{1}$ Oukaïmeden Observatory, High Energy Physics and Astrophysics Laboratory, FSSM, Cadi Ayyad University, \\ Marrakesh, BP 2390, Morocco \\ ${ }^{2}$ Department of Electrical and Computer Engineering, University of Illinois at Urbana-Champaign, Urbana, Illinois, USA \\ ${ }^{3}$ LESIA, Observatoire de Paris, PSL Research University, CNRS, Sorbonne Universités, UPMC Univ. Paris 06, Univ. Paris \\ Diderot, 5 place Jules Janssen, 92195 Meudon, France
}

Correspondence: Khalifa Malki (malki.khalifa@gmail.com)

Received: 13 March 2018 - Discussion started: 28 March 2018

Revised: 13 June 2018 - Accepted: 18 June 2018 - Published: 12 July 2018

\begin{abstract}
The present work explores the ionospheric and thermospheric responses to the 27-28 February 2014 geomagnetic storm. For the first time, a geomagnetic storm is explored in north Africa using interferometer, all-sky imager and GPS data. This storm was due to the arrival at the Earth of the shock of a coronal mass ejection (CME) associated with the solar flare event on 25 February 2014. A Fabry-Perot interferometer located at the Oukaïmeden Observatory $\left(31.206^{\circ} \mathrm{N}, 7.866^{\circ} \mathrm{W} ; 22.84^{\circ} \mathrm{N}\right.$ magnetic) in Morocco provides measurements of the thermospheric neutral winds based on observations of the $630 \mathrm{~nm}$ red line emission. A wide-angle imaging system records images of the $630 \mathrm{~nm}$ emission. The effects of this geomagnetic storm on the thermosphere are evident from the clear departure of the neutral winds from their seasonal behavior. During the storm, the winds experience an intense and steep equatorward flow from 21:00 to 01:00 LT and a westward flow from 22:00 to 03:00 LT. The equatorial wind speed reaches a maximum of $120 \mathrm{~m} \mathrm{~s}^{-1}$ for the meridional component at 22:00 LT, after the zonal wind reverses to the westward direction. Shortly after 00:00 LT a maximum westward speed of $80 \mathrm{~m} \mathrm{~s}^{-1}$ was achieved for the zonal component of the wind. The features of the winds are typical of traveling atmospheric disturbance (TAD)-induced circulation; the first TAD coming from the Northern Hemisphere reaches the site at 21:00 LT and a second one coming from the Southern Hemisphere reaches the site at about 00:00LT. We estimate the propagation speed
\end{abstract}

of the northern TAD to be $550 \mathrm{~m} \mathrm{~s}^{-1}$. We compared the winds to the DWM07 (Disturbance Wind Model) prediction model and find that this model gives a good indication of the new circulation pattern caused by storm activity, but deviates largely inside the TADs. The effects on the ionosphere were also evident through the change observed in the background electrodynamics from the reversal in the drift direction in an observed equatorial plasma bubble (EPB). Total electron content (TEC) measurements of a GPS station installed in Morocco, at Rabat $\left(33.998^{\circ} \mathrm{N}, 6.853^{\circ} \mathrm{W}\right)$, revealed a positive storm.

\section{Introduction}

The Sun is the energy provider of our planet through electromagnetic radiation, solar wind and the interplanetary magnetic field (IMF). It is a highly variable star with sporadic events consisting of outbursts of huge amounts of energy. Large solar flares are associated with an impulsive release of a large amount of ionizing emissions (UV, EUV, X-rays) that change the physical properties of the ionosphere, which may have a big impact on telecommunication and navigation, on a very small timescale. Coronal mass ejections (CMEs) are explosive outbursts of billions of tons of plasma originating from the corona. CMEs carry powerful magnetic fields and coronal plasma and are associated with shock waves. 
CMEs take from 1 to 4 days to travel to Earth, and interact with the solar wind and the IMF during their propagation. They can trigger geomagnetic storms when they interact with the Earth's magnetic field. Solar particle events are a release of relativistic charged particles - mainly protons and electrons produced in association with the flare or by the CME-associated shock. A large coronal hole facing the earth can also cause a geomagnetic storm. Many changes occur in the magnetosphere when an intense surge of solar wind or a coronal mass ejection reaches the Earth. The geomagnetic field can become highly variable, and all the currents flowing through the magnetosphere and the ionosphere change rapidly. In response, the composition and dynamics of the ionosphere and the thermosphere are highly affected.

According to the World Meteorological Organization, "space weather" designates the physical and phenomenological state of the natural space environment, including the Sun and the interplanetary and planetary environments. The associated discipline aims at observing, understanding and predicting the state of the Sun and of the planetary and interplanetary environments and their disturbances, with particular attention to the potential impacts of these disturbances on biological and technological systems. Our modern society depends on technological tools for telecommunication, navigation, positioning, space exploration and energy provision. The effects of space weather can cause satellite damage, radiation hazards to astronauts and airline passengers, telecommunication problems, outages of power and electronic systems and the endangerment of human life in our technical societies. As the importance of technology will inevitably increase in our daily lives there is a need to thoroughly understand the Sun/Earth system and space weather. The International Space Weather Initiative (ISWI), a program of international cooperation, was created to advance space weather science by a combination of instrument deployment, analysis and interpretation of space weather data.

It is within the framework of the ISWI program that the RENOIR (Remote Equatorial Nighttime Observatory of Ionospheric Region) experiment was deployed in Morocco on November 2013 at the Oukaïmeden Astronomical Observatory of Cady Ayyad University $\left(31.206^{\circ} \mathrm{N}, 7.866^{\circ} \mathrm{W}\right.$; $22.84^{\circ} \mathrm{N}$ magnetic). The RENOIR experiment consists of a Fabry-Perot (FPI) interferometer and a wide-angle viewing camera. The FPI makes measurements of the thermospheric neutral wind velocities and neutral temperatures using observations of the $630.0 \mathrm{~nm}$ emission caused by the dissociative recombination of $\mathrm{O}_{2}^{+}$. The wide-angle imaging system uses the same airglow emissions to provide measurements of ionospheric structures and irregularities. The main goal of this experiment is to characterize the midlatitude ionosphere and thermosphere by establishing the climatology of both the neutral winds and the instabilities taking place in the ionosphere as well as the coupling between the ionosphere and thermosphere during quiet-time conditions and during geomagnetic storms.
Thermospheric winds are driven primarily by pressure gradients due to the absorption of solar radiation and collisions between atmospheric constituents and precipitating auroral particles. During a geomagnetic storm, the energy input modifies the global circulation of the thermosphere, which profoundly influences the structure and composition of the ionosphere. Understanding the thermosphere-ionosphere coupling is the most challenging problem in space weather. It is within this context that we conduct thermospheric and ionospheric measurements over a midlatitude site in north Africa by using data from an interferometer, a GPS station and an all-sky imager. In the present paper, we analyze the ionospheric and thermospheric response to the 27-28 February 2014 geomagnetic storm. We illustrate the evident departure of the neutral winds from their normal behavior. A reversal in the background ionospheric electric field was evident through the dynamics of the plasma bubbles that occurred that night (Blanc and Richmond, 1980; Fejer et al., 2017). The drift velocity of the EPB (equatorial plasma bubble) is compared to the zonal neutral winds in order to investigate the dynamo. Total electron content (TEC) measurements demonstrate the nature of the ionospheric storm precisely. We have also conducted a comparison of the neutral winds with the DWM07 (Disturbance Wind Model) predictions. This is the first time that a case study of a geomagnetic storm has been achieved in north Africa by using FabryPerot interferometer data of the thermosphere. Additionally, this is the first coincident study of a storm using a groundbased FPI and an all-sky imager in this sector.

\section{Source of the geomagnetic storm}

On 25 February 2014 at 00:49 UT, an X4.9-class flare was produced in NOAA active region (AR) 1990 close to the east limb. It was associated with a halo CME, with a speed of more than $2000 \mathrm{~km} \mathrm{~s}^{-1}$ (see CDAW CME catalog, Yashiro et al., 2004). The flare-CME event produced a solar energetic particle event observed by many spacecrafts (Lario et al., 2016). The CME-associated shock reached the Advanced Composition Explorer (ACE) satellite on 27 February 2014 at $\sim 16: 00$ UT (see e.g., Lario et al., 2016) with an increase in the density, temperature, velocity of the solar wind and the amplitude of the interplanetary magnetic field and an inversion of the $\mathrm{Bz}$ magnetic field component. The resultant geomagnetic storm was characterized by the variations of the Kp, Dst (disturbance storm time) and auroral electrojet (AE) geomagnetic indices shown in Fig. 1. The Dst index is indicative of the total energy content of the particles responsible for the ring current. Geomagnetic storms with $\mid$ Dst $\left.\right|_{\max }$ between 100 and $200 \mathrm{nT}$ are classified as intense, with $\mid$ Dst $\left.\right|_{\max }>200 \mathrm{nT}$ as super-intense and other events with $\mid$ Dst $\left.\right|_{\max }$ between 50 and $100 \mathrm{nT}$ classified as moderate (Singh et al., 2017). According to this classification, a moderate storm took place as observed during 27 Febru- 


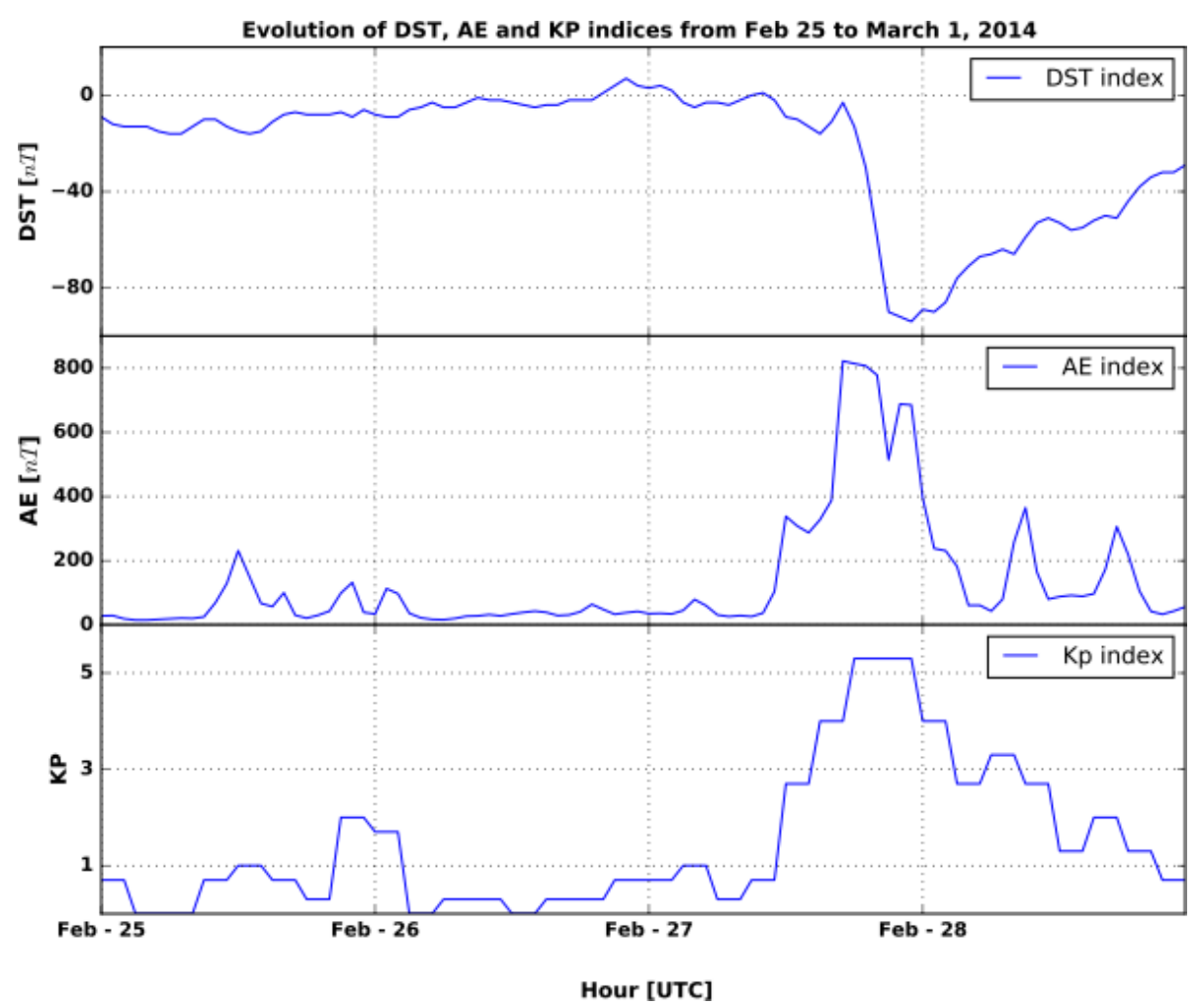

Figure 1. Time variations of the Kp, Dst and AE geomagnetic indices for the period 25-28 February 2014.

ary 2014 at $\sim 16: 30 \mathrm{UT}$ with $|\mathrm{Dst}|_{\max } \simeq 90 \mathrm{nT}$ associated with the $\mathrm{CME}$ shock arrival. The $\mathrm{AE}$ index variations, based on high-latitude magnetograms (AE 400-500 nT weak geomagnetic activity and $\mathrm{AE} \sim 1000 \mathrm{nT}$ intense geomagnetic activity), also show moderate storm activity on 27 February 2014 at 16:30 UT, with the AE index attaining values greater than $800 \mathrm{nT}$. The NOAA real-time observed Kp index reached 5 during the synoptic period 16:00-18:00 UT on 27 February following the CME shock arrival. These intense variations in all geomagnetic indices are due to the arrival and interaction with Earth's magnetosphere of the CME from NOAA AR 11990. As the energy is deposited into the Earth's geospace system, effects are expected to propagate from high to low latitudes, modifying the Earth's thermosphereionosphere system. Below, we use measurements obtained from an observatory in Morocco to study these changes at midlatitudes.

\section{Data and instrumentation}

Figure 2 shows the locations of the instruments used to collect data from the ionosphere and thermosphere. These instruments consist of an FPI and a wide-angle camera (Makela et al., 2011) located at the Oukaïmeden Observatory in Morocco $\left(31.206^{\circ} \mathrm{N}, 7.866^{\circ} \mathrm{W} ; 22.84^{\circ} \mathrm{N}\right.$ magnetic; $2700 \mathrm{~m}$ of altitude). The FPI alternates between observations of the

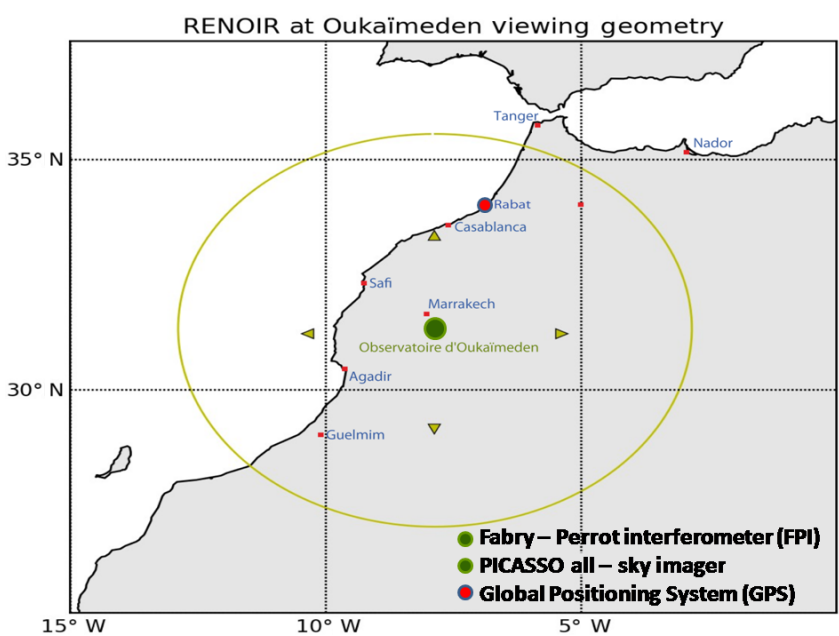

Figure 2. Viewing geometry (yellow circle) of the RENOIR experiment centered at Oukaïmeden Observatory $\left(31.206^{\circ} \mathrm{N}, 7.866^{\circ} \mathrm{W}\right.$; $22.84^{\circ} \mathrm{N}$ magnetic). The city of Rabat $\left(33.998^{\circ} \mathrm{N}, 353.1457^{\circ} \mathrm{E}\right)$ locating a GPS system is included in the viewing area. The yellow triangles indicate the viewing directions of the Fabry-Perot interferometer.

thermosphere at locations $250 \mathrm{~km}$ to the east, west, north and south of the observatory, and the viewing area of the camera covers a circle with $\sim 500 \mathrm{~km}$ radius. The city of Rabat 
$\left(33.998^{\circ} \mathrm{N}, 6.854^{\circ} \mathrm{W}\right)$ where the GPS is located is included in that viewing area.

The FPI measures the Doppler shifts and Doppler broadenings of the $630.0 \mathrm{~nm}$ spectral emission and infers the thermospheric wind and temperatures for an altitude around $250 \mathrm{~km}$. To be able to collect incident light from any direction, a system of two parallel mirrors called a sky scanner is used which points in six directions during each cycle (laser, zenith, north, east, south and west). The incident light passes through a narrowband interference filter $(630.0 \mathrm{~nm})$ and an etalon before being focused onto the CCD (charge-coupled device) plane by a lens. An interference pattern is captured by the CCD and processed to produce estimates of the neutral wind velocity and temperature (Harding et al., 2014). A frequencystabilized HeNe laser is used to provide an estimate of the instrument's optical transfer function and to characterize the instrument's drift over the night.

The all-sky imaging system consists of a lens system, a five position filter wheel and a CCD device. One filter is used to isolate the $630 \mathrm{~nm}$ emission, allowing plasma bubbles, medium-scale traveling ionospheric disturbances, gravity waves and ionospheric irregularities in general to be visualized (Makela and Miller, 2008; Duly et al., 2013).

Numerous studies have shown that the GPS is an effective tool for characterizing the ionosphere through measuring the TEC, which represents the total number of electrons integrated along the path from the receiver to each GPS satellite (Sethi et al., 2001; Boutiouta and Belbachir, 2006; Chauhan and Singh, 2010; Ouattara et al., 2011). Here, we present the vertical total electron content (VTEC) over Rabat $\left(33.998^{\circ} \mathrm{N}, 6.853^{\circ} \mathrm{W}\right)$ obtained from the International GPS Geodynamics Service (IGS) network. The GPS data needed to determine the TEC are (1) data extracted from files stored in RINEX (Receiver INdependent EXchange) format, (2) data in IONEX format (IONosphere EXchange Format), (3) almanacs of the GPS satellite position and (4) the satellite clock biases. The procedure for extracting the TEC from GPS data is well documented in the literature (Sardon et al., 1994; Klobuchar, 1996; Schaer, 1999; Zoundi et al., 2012; Christian et al., 2013).

\section{Thermospheric and ionospheric response}

\subsection{Thermospheric wind response}

The day-night difference in the solar heating is the primary source that controls the thermospheric wind circulation during quiet-time conditions. Another important secondary source is upward propagating tides. During geomagnetic storms, joule heating is enhanced by strong high-latitude electric currents and by collisions of neutrals with convecting ions. These highly variable sources cause disturbances to thermospheric winds which will further affect the global ionospheric dynamo (Blanc and Richmond, 1980). In disturbed geomagnetic conditions, thermospheric neutral winds exhibit large deviations from their quiet-time climatological behavior and can drive large changes in the ionospheric plasma density, composition, temperature and electrodynamics (Richmond and Matsushita, 1975; Rishbeth and Edwards, 1989; Fuller-Rowell et al., 1994; Buonsanto, 1999; Emmert et al., 2004; Mendillo, 2006; Meriwether, 2008).

Before commenting on the behavior of thermospheric winds over Oukaïmeden Observatory during the study period ( 25 to 28 February 2014), we first begin by summarizing their basic climatology (Kaab et al., 2017). In summertime, the meridional winds are equatorward for the entire night, reaching a maximum speed of $75 \mathrm{~m} \mathrm{~s}^{-1}$. A poleward component is present in winter, in the early evening hours until 21:00 UT. The peak in equatorward flow shifts throughout the year from 23:00 UT during the spring equinox to 02:00 UT during the autumn equinox. The zonal winds are eastward during the entire night, with typical speeds around $50 \mathrm{~m} \mathrm{~s}^{-1}$ during the early evening hours, 75 to $100 \mathrm{~m} \mathrm{~s}^{-1}$ around 21:00 UT and almost zero before dawn in wintertime. A westward reversal is present shortly before dawn in local summer.

Figure 3 shows the geographic meridional and zonal winds measured with the FPI during 24, 25, 27 and 28 February 2014. The 26 February measurements are missing due to a power outage. The FPI measures line of sight (LOS) winds in four cardinal directions - east, west, north and south. The east and west LOS winds are zonal winds and the north and south LOS winds are meridional winds. The FPI data have been binned into half-hour bins. The error bars represent variability (mean $\pm \sigma$ ) within each $30 \mathrm{~min}$ time bin. The quiet time refers to data with $3 \mathrm{~h} \mathrm{Kp}<4$. The average quiet-time wind components derived from measurements are in red, and the quiet-time daily variability is illustrated by the shaded purple area. Positive wind values are northward for the meridional winds and eastward for the zonal ones, respectively. We can clearly notice that the effect of the storm on 27 February 2014 is very noticeable on both the meridional and zonal winds that have largely departed from their quiet-time climatology. Figure 1 indicates that $\mathrm{Kp}$ is low until $\sim$ 17:00 UT on 27 February, when Kp grows to 4 and eventually reaches 5 . The meridional wind was equatorward and increased sharply after 21:00 UT to a speed of about $140 \mathrm{~m} \mathrm{~s}^{-1}$ and reversed sharply to a poleward direction around 01:00 UT. They remain poleward with a low speed until 04:00 UT, when they reverse again to an equatorward direction. Instead of being eastward during the entire night, the zonal wind (on 27 February) starts eastward in the early evening, with lower speeds than the quiet-time climatology, reverses westward at 22:00 UT, achieving a maximum speed of $100 \mathrm{~m} \mathrm{~s}^{-1}$ around 00:00 UT, and reverses back to an eastward direction around 03:00 UT.

The steep and abrupt changes in the meridional winds are the signature of thermospheric traveling atmospheric disturbances (TADs) flowing over the area covered by the Oukaïmeden FPI measurements. The first TAD coming from 

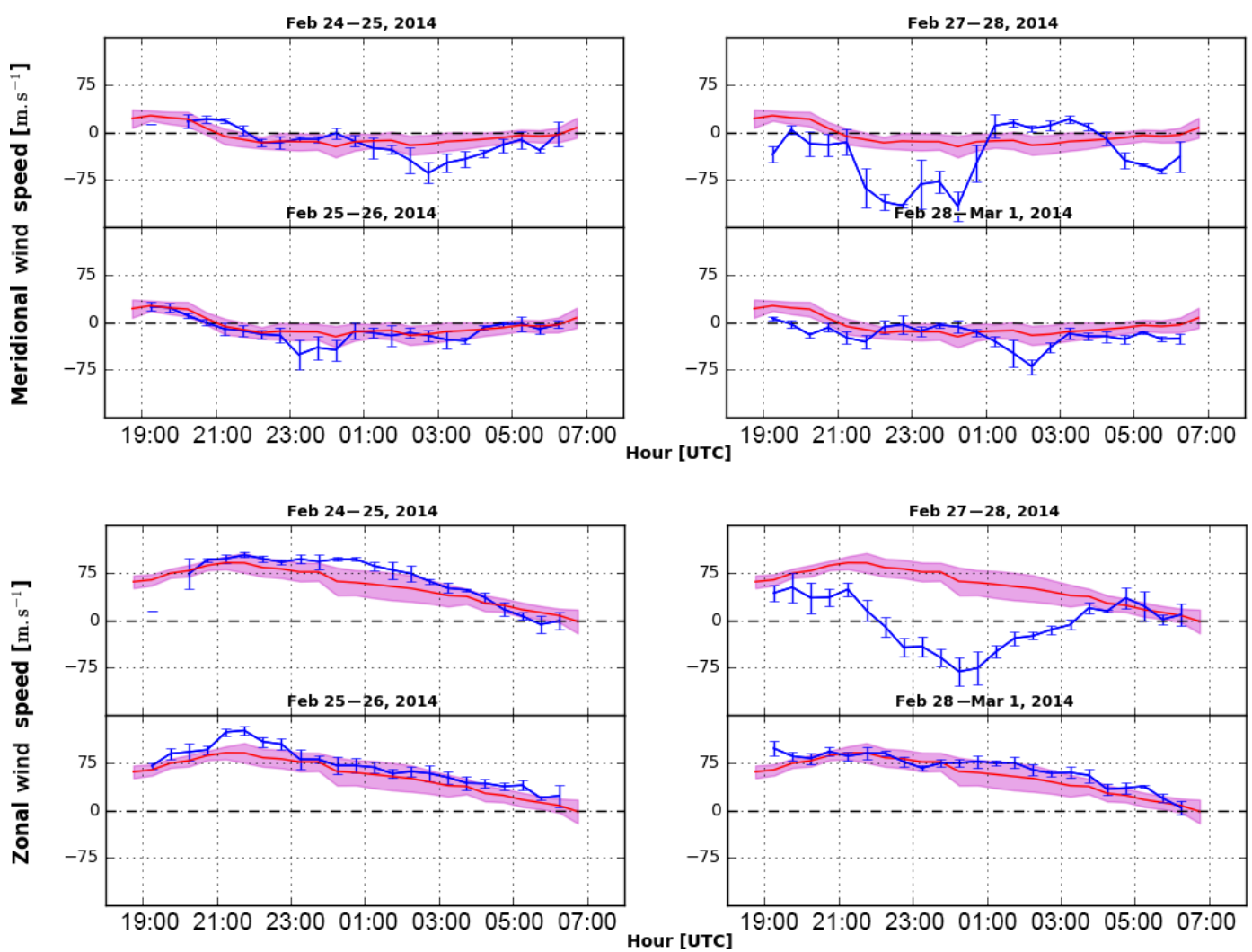

Figure 3. Thermospheric geographic meridional and zonal winds measured by the Fabry-Perot interferometer (FPI) over Oukaïmeden Observatory $\left(31.206^{\circ} \mathrm{N}, 7.866^{\circ} \mathrm{W} ; 22.84^{\circ} \mathrm{N}\right.$ magnetic). The FPI winds are estimated from the $630 \mathrm{~nm}$ airglow emission caused by dissociative recombination of $\mathrm{O}_{2}^{+}$. The dates of measurements are the 24, 25, 27 and 28 February 2014. The red line refers to the monthly average of the nights with Kp strictly less than 4 . The blue line shows the meridional (zonal) measurements during the night and the magenta area denotes the daily variability during February 2014.

the Northern Hemisphere was captured around 21:00 UT, and the second TAD coming from the Southern Hemisphere was captured around 00:00 UT. At this point we find it interesting to represent the separate components of the meridional wind. Figure 4 shows the meridional wind estimates made facing the north and south at an elevation angle of $45^{\circ}$. These measurements are separated from one another by $500 \mathrm{~km}$. In less than an hour the northern component of the wind gained a speed of almost $150 \mathrm{~m} \mathrm{~s}^{-1}$ towards the equator. The effect of the TAD coming from the North Pole lasted for about $4 \mathrm{~h}$, during which the northern component had a higher speed than the southern one. The southern component reacted to the TAD with a delay of approximately 15 min. Our estimation then of the speed of the TAD over the studied area is about $550 \mathrm{~m} \mathrm{~s}^{-1}$. Xiong et al. (2015) used the superposed epoch analysis of CHAMP zonal wind observations from 2001 to 2005 and estimated the typical propagation speed of TADs to be $610 \mathrm{~m} \mathrm{~s}^{-1}$. From Fig. 4, the meridional winds reacted to the transequatorial southern TAD at 00:20. Its effect lasted for $3.5 \mathrm{~h}$ during which the southern location had a larger speed than the northern one. From 22:00 to 00:00 UT, the equatorward wind encountered some steep reactive effects, especially from 23:00 to 00:00 LT, when the speed of the northern meridional wind lost about $100 \mathrm{~m} \mathrm{~s}^{-1}$ in $20 \mathrm{~min}$. Usually the quiet-time northward surge of the wind related to the MTM (midnight temperature maximum) phenomenon occurred during that month (February 2014) on average between 22:30 and 00:30 UT with an average amplitude of $20 \mathrm{~m} \mathrm{~s}^{-1}$. The northward surge that occurred between 23:00 and 00:00 UT on 27 February 2014 might be due to the enhancement of the MTM phenomenon by the storm circulation.

The thermospheric response, induced by high-latitude heat input drives a global circulation of winds flowing from high to low latitudes (Buonsanto, 1989, 1990), creating largescale atmospheric waves (Richmond, 1979) that propagate on a global scale. Due to Coriolis forces, a subsequent change in the zonal circulation flowing westward takes place. The storm-induced atmospheric waves propagates to low latitudes and into the opposite hemisphere. The local impression of this global picture of the storm was captured during the 27 February event (see Fig. 3). Indeed, the poleward surge occurred at 21:00 UT and drove the zonal wind to flow to the west at 22:00 UT. This result of westward and equatorward 


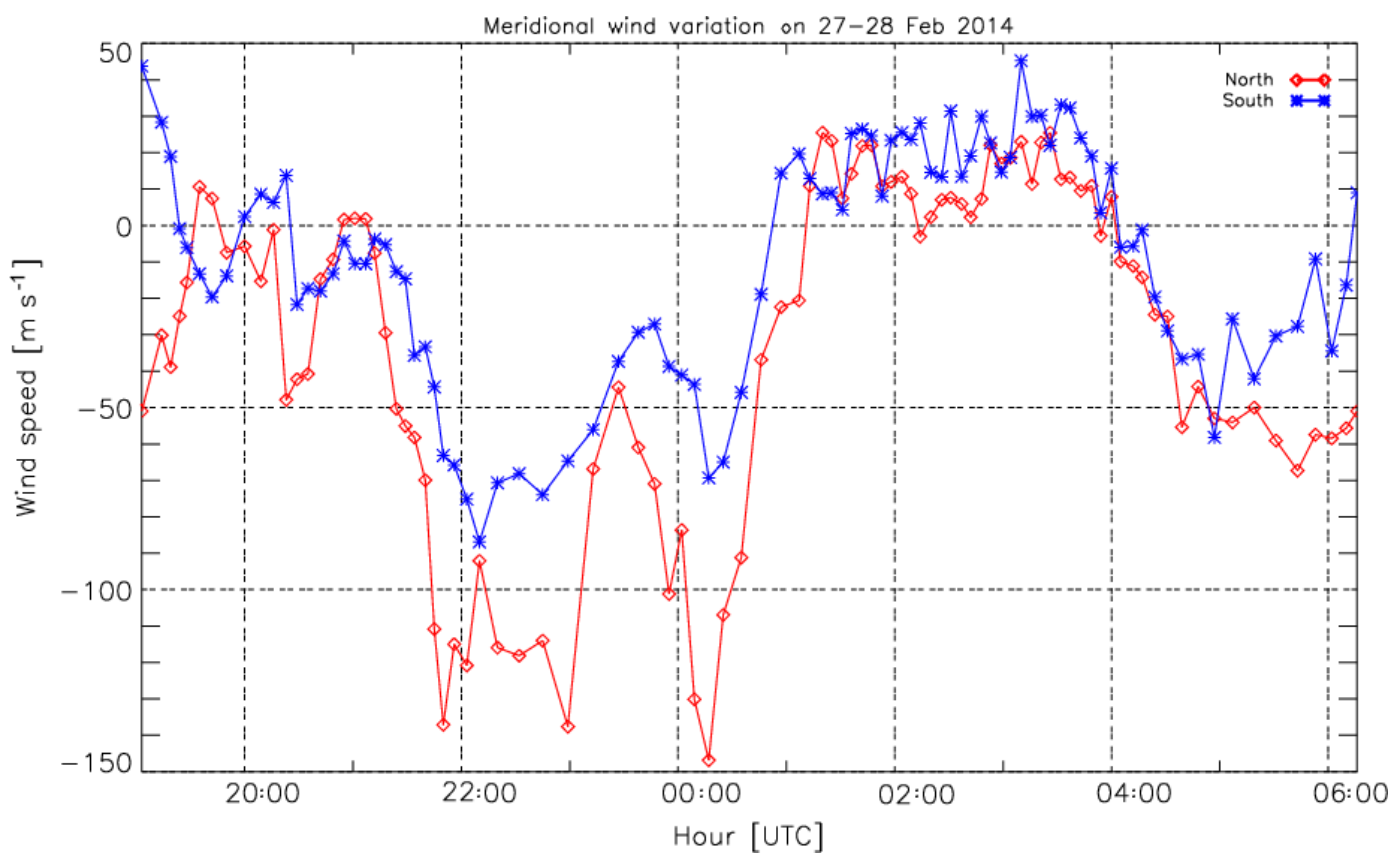

Figure 4. Thermospheric north- and south-facing components of the meridional wind measured by the Fabry-Perot interferometer (FPI) over Oukaïmeden Observatory $\left(31.206^{\circ} \mathrm{N}, 7.866^{\circ} \mathrm{W} ; 22.84^{\circ} \mathrm{N}\right.$ magnetic).

winds during the magnetic storm is consistent with previous results obtained using ground-based Fabry-Perot interferometers (Makela et al., 2014; Zhang et al., 2015). Xiong et al. (2015) use the CHAMP zonal wind observations from 2001 to 2005 to investigate the global features of the disturbance winds during magnetically disturbed periods. They report that the disturbance zonal wind is mainly westward and increases with magnetic activity and latitude. Emmert et al. (2004) report westward and equatorward nighttime disturbed winds at midlatitudes.

Emmert et al. (2008) present an empirical wind model (DWM07) representing average geospace-storminduced perturbations of upper thermospheric neutral winds. In constructing their model, they used data from the Wind Imaging Interferometer on board the Upper Atmosphere Research Satellite, the Wind and Temperature Spectrometer on board Dynamics Explorer 2, and seven ground-based FPIs. The wind derived from their empirical model is dependent on three parameters: magnetic latitude, magnetic local time and the $3 \mathrm{~h} \mathrm{Kp}$ geomagnetic activity index. To quantify the geomagnetically disturbed thermosphere, they established a quiet-time reference that they subtracted from each measurement (Emmert et al., 2008). We removed the average quiet-time wind from the wind measured on 27 February and compared this with the model prediction by DWM07 for this storm. Results are shown in Fig. 5. The model predicts westward disturbed zonal winds with a maximum speed of $60 \mathrm{~m} \mathrm{~s}^{-1}$ from 19:00 UT until 03:00 UT. The measured disturbance wind is westward during the whole night but with a maximum speed of $140 \mathrm{~m} \mathrm{~s}^{-1}$ around 00:00 UT. The speed is then much higher than expected by the DWM07 empirical model. The meridional disturbed wind is clearly equatorward (Fig. 5) until 00:00 UT, with a particularly steep increase starting at 21:00 UT, reaching a maximum speed of $90 \mathrm{~m} \mathrm{~s}^{-1}$ at 22:30 UT. An abrupt decreasing meridional speed occurs shortly after 00:00 UT, reversing the disturbed winds to a northward direction at 01:00 UT. However, the predicted meridional winds are extremely low, with a reversal time of 23:00 UT instead of 01:00 UT for our measurements. The general feature of the wind agrees with the model predictions, but we measure faster speeds and the effects of traveling atmospheric disturbances were clearly noticeable from our measurements and absent from the model predictions. The DWM07 model predictions provide a good indication of the new circulation pattern caused by storm activity, but it does not include the effects of TADs. This is expected because DWM07 is a climatological model. It does not include dynamics, so it cannot model TADs. TADs, when propagating from polar to equatorial regions, cause an uplift in the Fpeak height $(H m \mathrm{~F} 2)$, which in turn has a subsequent effect on the increase of the F-peak density $(\mathrm{NmF} 2)$. Therefore, largescale traveling ionospheric disturbances (TIDs), consisting of sequential rises and falls in $\mathrm{Hm} \mathrm{F} 2(\mathrm{Nm} \mathrm{F} 2)$, happen. Models of storm response must then include dynamical wind effects, in addition to changes in the circulation pattern, in order to reproduce realistic ionospheric responses. 


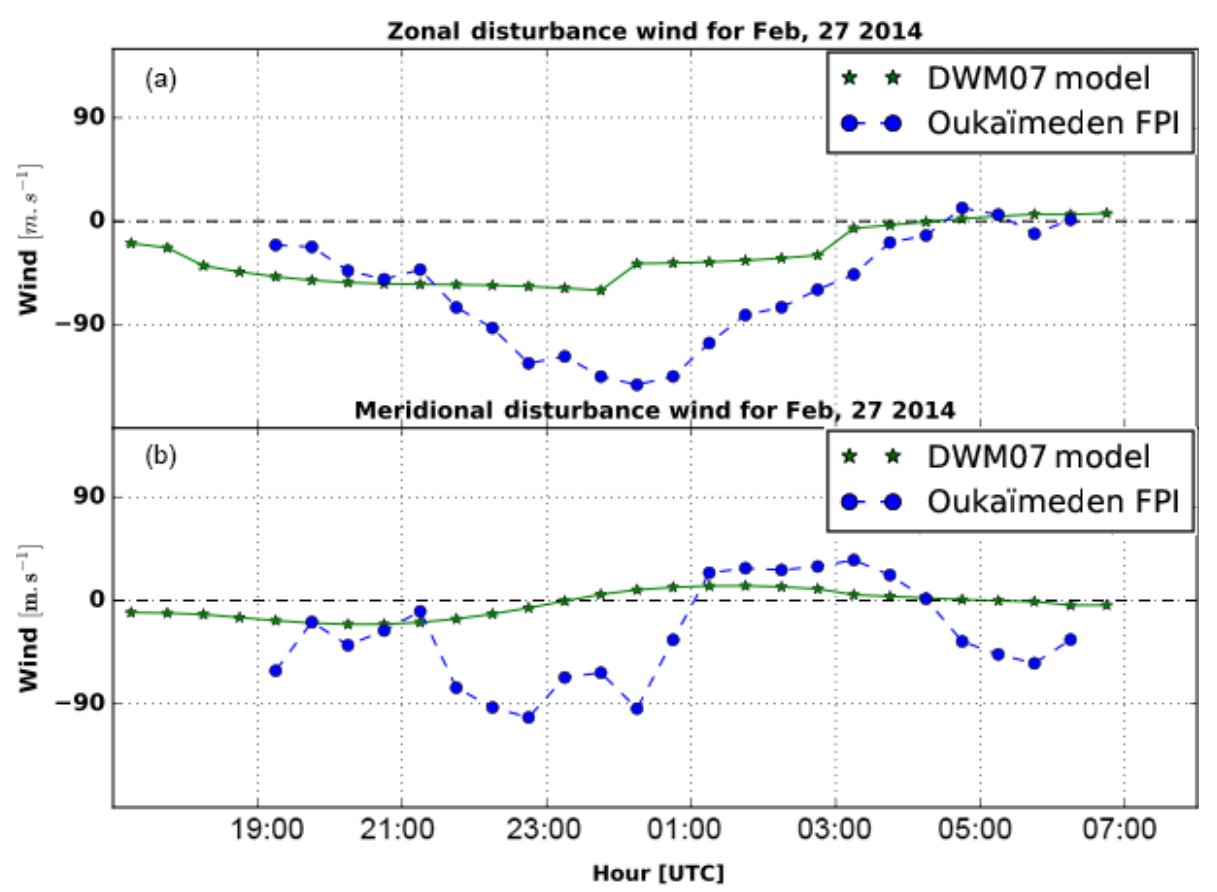

Figure 5. Comparison of zonal (a) and meridional (b) disturbance winds predicted by the DWM07 (Disturbance Wind Model; green stars) with disturbed thermospheric meridional and zonal winds obtained over Oukaïmeden Observatory from which the monthly quiet-time average (with $\mathrm{Kp}<4$ ) has been removed.

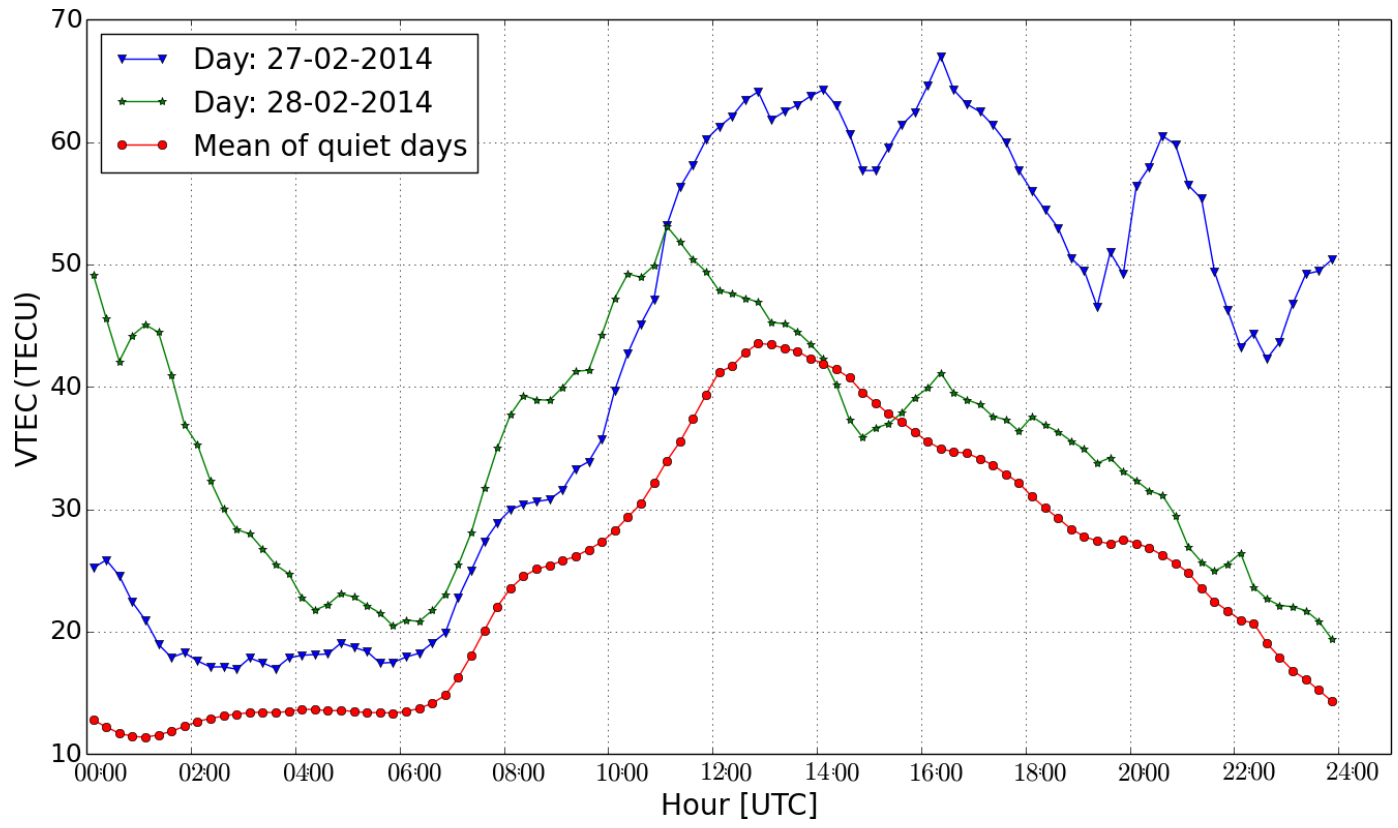

Figure 6. Total electron content (TEC) measured over Rabat $\left(33.998^{\circ} \mathrm{N}, 6.854^{\circ} \mathrm{W}\right)$.

\subsection{Ionospheric electron density response}

The estimated TEC measured from a GPS station installed in Rabat $\left(33.998^{\circ} \mathrm{N}, 6.854^{\circ} \mathrm{W}\right.$, geographic) is illustrated in Fig. 6. This figure contains the TEC for the 27 and 28 February 2014 and the February 2014 quiet days average
$(3 \mathrm{~h} \mathrm{Kp}<4)$. We can divide the quiet-time shape mainly into three regions: region 1 from 07:00 to 13:00 UT, when the TEC increases almost linearly from 15 to 45 TECU; region 2 from 13:00 to 00:00 UT, when the TEC decreases almost linearly from 45 to $15 \mathrm{TECU}$; and region 3 from 00:00 to 


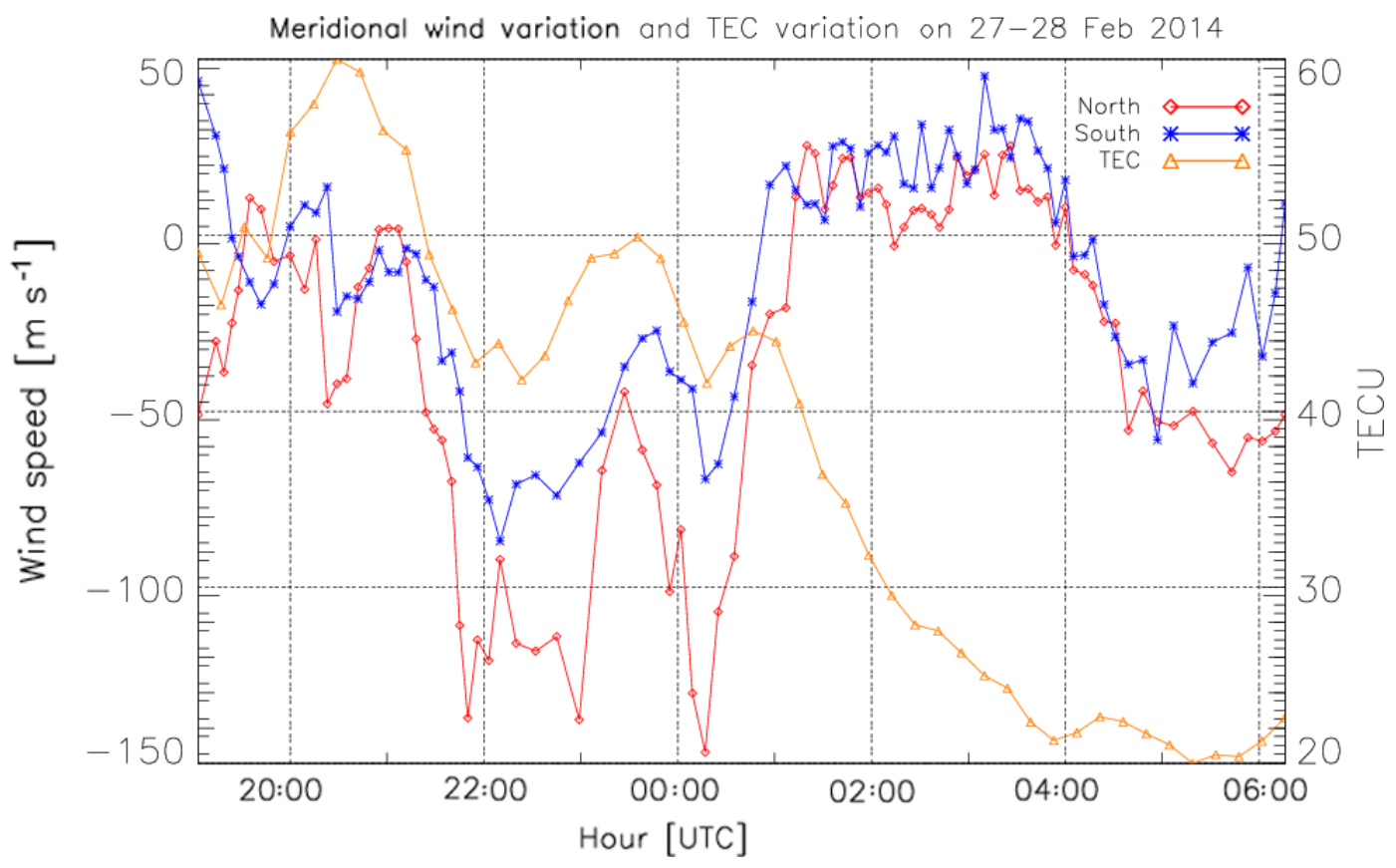

Figure 7. Total electron content (TEC) measured over Rabat $\left(33.998^{\circ} \mathrm{N}, 6.854^{\circ} \mathrm{W}\right)$ and thermospheric meridional wind north- and southfacing components, measured by the Fabry-Perot interferometer (FPI) over Oukaïmeden Observatory $\left(31.206^{\circ} \mathrm{N}, 7.866^{\circ} \mathrm{W} ; 22.84^{\circ} \mathrm{N}\right.$ magnetic).

07:00 UT, when the TEC is almost constant. The rate of the increase in region 1 is about $5 \mathrm{TECU} \mathrm{h}^{-1}$, and the rate of the decrease in region 2 is about $2.7 \mathrm{TECU} \mathrm{h}^{-1}$. We can clearly notice the positive storm on 27 February, with a maximum TEC of 65 TECU (around 13:00 UT), remaining high for some hours and achieving 50 TECU at 00:00 UT. In the early hours of 28 February, from 01:00 to 04:00 UT, the decrease is steep, with an approximate rate of $8.3 \mathrm{TECU} \mathrm{h}^{-1}$. During the 28 February, the TEC was still higher than quiet-time behavior. The observed difference during the early hours was about 40 TECU and about 20 TECU during the day and it diminished to 10 TECU during the night. This result is consistent with previous observations of positive storms in the winter hemisphere and negative ones in the summer hemisphere (Fuller-Rowell et al., 1994, 1998)).

We observe oscillations of the TEC on the 27 February between 14:00 and 00:00 UT and in the early hours of 28 February. As the meridional wind plays an important role in the dynamics of the ionosphere, in Fig. 7 we present the evolution of the TEC, along with the meridional wind measured to the north and south. Only parts of region 2 and region 3 are compared. In region 3, we observe a steep decrease of the TEC and an absence of correlation with the meridional winds. In this region, on a normal day, the TEC is small and does not change during this time. On the storm day during this time, the TEC starts high but returns quickly to its normal values. In region 2, between 19:00 and 00:00 UT, we can notice that the TEC correlates in some ways with the meridional winds.
In fact, when the meridional winds are more equatorward, we observe a decrease of the TEC.

This observation contrasts with the quiet daytime behavior, in which a poleward wind drags the ionosphere down to regions of increased mean molecular mass, causing a faster recombination and a reduced ionospheric density (i.e., a negative correlation between poleward winds and plasma density). The reason a positive correlation is observed is likely due to transport caused by the TAD. At night, plasma production is near to zero, yet increases in TEC are seen. This can only be due to transport. This observation is consistent with previous studies discussing the negative correlation between $h m \mathrm{~F} 2$ and $N m \mathrm{~F} 2$ during the passage of TADs, at least in the initial phase (Bauske and Prölss, 1997 and Lee et al., 2002). (Lee et al., 2004) used ionosondes, ROCSAT-1 satellite data and the Thermosphere Ionosphere Electrodynamics General Circulation Model (TIEGCM) to study the ionospheric features of TADs during the 6-7 April 2000 magnetic storm. Their observations and corresponding TIEGCM simulations show a negative initial correlation between $N m \mathrm{~F} 2$ and $\mathrm{HmF} 2$ caused by equatorward wind surges at various locations from midlatitudes to the equator. A more detailed study of the processes involved in the TEC observations shown here would require co-located observations of $h m \mathrm{~F} 2$ and $N m \mathrm{~F} 2$.

\subsection{Electrodynamic response}

Figure 8 shows a sequence of OI $630.0 \mathrm{~nm}$ airglow images illustrating the spatial characteristics and the time evolution of 


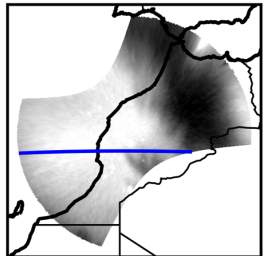

27 Feb 21:00 UT

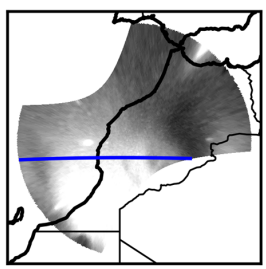

28 Feb 00:01 UT
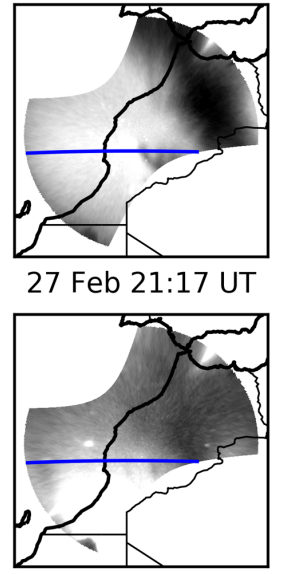

28 Feb 00:17 UT

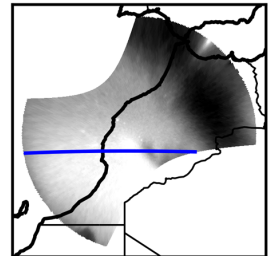

27 Feb 21:33 UT

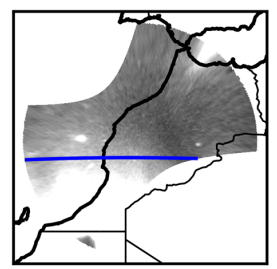

28 Feb 00:34 UT

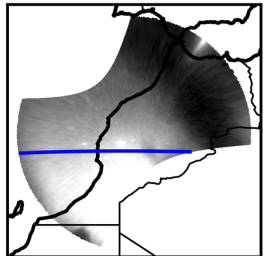

27 Feb 21:50 UT

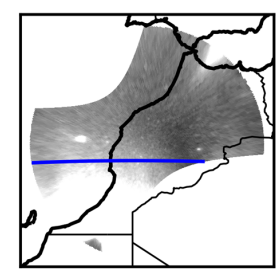

28 Feb 00:50 UT

Figure 8. Sequence of OI $630.0 \mathrm{~nm}$ images showing spatial characteristics and time evolution of EPBs from 21:00 to 00:50 UT on 27-28 February 2014.

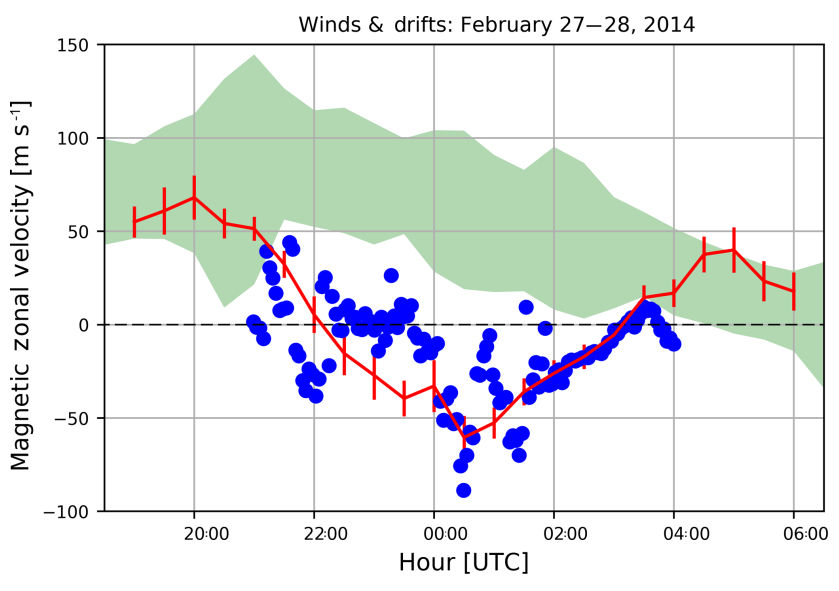

Figure 9. Estimated plasma drifts and neutral winds for the night of 27 February 2014. The plasma drift estimates from crosscorrelations are marked as blue dots. The zonal neutral winds are plotted in red, with error bars for the measurement uncertainties. The green shaded region displays the typical range of quiet-time zonal neutral winds for February 2014.

EPBs observed over Oukaïmeden during the night of 27-28 February 2014. The dark structures correspond to EPB signatures. While bubble motion is eastward in the early evening of 27 February from 21:00 until 00:50 UT, the plasma bubbles drift westward on 27 February 22:00 UT. This time of the reversal of the plasma drift corresponds to the time when the zonal wind starts reversing westward. This reversal of the drift direction of the plasma bubbles is a consequence of the reversal of the background electric field direction as driven by the neutral wind disturbance dynamo. This is consistent with both simulation and observational results (Blanc and Richmond, 1980; Fejer and Emmert, 2003). However, these are the first joint observations of EPBs during storm times from both a ground-based FPI and imager over north Africa.

According to Blanc and Richmond (1980), during a magnetic storm, both the electric field and current at low latitudes vary in opposition to their normal quiet-day behavior in the sequence of an electrodynamic phenomenon. During a geomagnetic storm, a Hadley cell is created with equatorward and westward winds, which in turn drive equatorward Pedersen currents, resulting in the generation of a poleward electric field, a westward $\boldsymbol{E} \times \boldsymbol{B}$ drift and an eastward current which in turn create an anti-Sq type of current vortex.

Figure 9 shows the EPB zonal drift velocity, which is estimated from the images in Fig. 8 by performing a crosscorrelation analysis. We assume here that the EPB drift velocity is a good proxy for the background plasma drift velocity. Cross sections of the image are taken along a line of constant magnetic latitude (the blue line in Fig. 8), and a crosscorrelation is taken between each image and an image $15 \mathrm{~min}$ later. The time lag corresponding to the maximum correlation is used to determine a velocity, under the assumption that structures in the image do not change significantly over $15 \mathrm{~min}$. The zonal drifts estimated throughout the night can then be compared to the zonal neutral winds to investigate the dynamo during storm time conditions. Figure 9 also shows the average measured zonal winds and quiet-time monthly average zonal winds for this storm. Due to the small magnetic declination at Oukaïmeden $\left(\sim 2^{\circ}\right)$, the magnetic and geographic winds are nearly identical, allowing this comparison. Two major observations can be drawn from this figure: first, the neutral winds are indeed westward, indicating forcing from the geomagnetic storm, and second, the EPB drifts tend to closely match the neutral winds, indicating that the dynamo is fully activated during this storm. 


\section{Summary and conclusion}

The effect of the 27 February 2014 geomagnetic storm on the thermosphere and the ionosphere is discussed in this paper. Thermospheric winds were inferred from Fabry-Perot interferometer measurements deployed at Oukaïmeden Observatory $\left(31.206^{\circ} \mathrm{N}, 7.866^{\circ} \mathrm{W} ; 22.84^{\circ} \mathrm{N}\right.$ magnetic). The ionospheric response of the storm was also analyzed using the VTEC data and a wide-angle imaging camera. The source of the geomagnetic and ionospheric storm was briefly investigated in Sect. 2.

The zonal and meridional components of the winds were compared with their quiet-time climatology to study the effect of the storm on the wind dynamics. Traveling atmospheric disturbances were evident in the meridional winds the first one coming from the Northern Hemisphere and the second one coming from the Southern Hemisphere. From the time delay in the response of the northern and southern components of the meridional wind, we estimate the speed of the northern TAD to be $\sim 550 \mathrm{~m} \mathrm{~s}^{-1}$.

We compared the storm-induced components of the winds to the DWM07 model and concluded that while the model gives a good approximation of the wind pattern, it largely departs from its normal behavior inside the TAD. Traveling atmospheric disturbances trigger traveling ionospheric disturbances and to predict the effect of the storm on the ionosphere, a model must include the dynamics of the winds and the time since the storm started.

The VTEC response of the storm was positive as expected during this time of the year. Evidence of TIDs was noticeable from the TEC pattern, and this correlates with the meridional components of the wind until 01:00 UT on 28 February. We have observed a negative correlation between $\mathrm{Hm} \mathrm{F} 2$ and $N m \mathrm{~F} 2$ during the passage of the TAD.

The ionospheric response of the storm was also analyzed through the observation of equatorial plasma bubbles. We observe a reversal in the drift direction, which indicates a reversal of the background electric field direction due to the neutral wind disturbance dynamo. This is the first time that a case study of a geomagnetic storm has been achieved in north Africa by using Fabry-Perot interferometer data of the thermosphere. Additionally, this is the first coincident study of a storm using a ground-based FPI and an all-sky imager in this sector.

Data availability. The LOS neutral wind data and camera images used in this study are freely available for use in the Madrigal database. Please contact Jonathan J. Makela (jmakela@illinois.edu) before using these data. The GPS data used in this study are freely available for use from the International GPS Geodynamics Service (IGS, 2018) (ftp://data-out.unavco.org/pub/rinex/obs/, last access: 6 July 2018) network.

\author{
The Supplement related to this article is available \\ online at https://doi.org/10.5194/angeo-36-987-2018- \\ supplement.
}

Author contributions. $\mathrm{KM}, \mathrm{AB}$ and $\mathrm{ZB}$ mainly contributed to this work. MK and KE provided the neutral wind data and GPS data. JM, BH and DJF conducted the analysis of the camera data and extracted the plasma bubble drift velocity. They significantly contributed to the corrections and structure of the paper. NV contributed to the solar part. All authors participated in the writing and all commented on the paper.

Competing interests. The authors declare that they have no conflict of interest.

Acknowledgements. Work at the University of Illinois, including for the deployment of the instrumentation to Morocco, was supported by National Science Foundation CEDAR grants AGS 11-38998 and AGS 14-52291 as well as by NASA grant NNX14AD46G. The authors would like to thank the Oukaïmeden Observatory and its staff for their support and assistance to the FPI operations. The authors would like to thank Christine AmoryMazaudier and Rolland Fleury for help in training schools and GPS data. The authors would like to thank all referees for help in evaluating this paper.

The topical editor, Petr Pisoft, thanks two anonymous referees for help in evaluating this paper.

\section{References}

Bauske, R. and Prölss, G.: Modeling the ionospheric response to traveling atmospheric disturbances, J. Geophys. Res.-Space, 102, 14555-14562, 1997.

Blanc, M. and Richmond, A. D.: The ionospheric disturbance dynamo, J. Geophys. Res.-Space, 85, 1669-1686, https://doi.org/10.1029/JA085iA04p01669, 1980.

Boutiouta, S. and Belbachir, A. H.: Magnetic Storms Effects on the Ionosphere TEC through GPS data, Information Technology Journal, 5, 908-915, 2006.

Buonsanto, M. J.: Comparison of incoherent scatter observations of electron density, and electron and ion temperature at Millstone Hill with the International Reference Ionosphere, J. Atmos. Terr. Phys., 51, 441-468, 1989.

Buonsanto, M. J.: Observed and calculated F2 peak heights and derived meridional winds at mid-latitudes over a full solar cycle, J. Atmos. Terr. Phys., 52, 223-240, 1990.

Buonsanto, M. J.: Ionospheric storms A review, Space Scie. Rev., 88, 563-601, 1999.

Chauhan, V. and Singh, O.: A morphological study of GPS-TEC data at Agra and their comparison with the IRI model, Adv. Space Res., 46, 280-290, 2010.

Christian, Z., Ouattara, F., Emmanuel, N., Rolland, F., and Francois, Z.: CODG TEC variation during solar maximum and minimum over Niamey, European Scientific Journal, 9, 74-80, 2013. 
Duly, T. M., Chapagain, N. P., and Makela, J. J.: Climatology of nighttime medium-scale traveling ionospheric disturbances (MSTIDs) in the Central Pacific and South American sectors, Ann. Geophys., 31, 2229-2237, https://doi.org/10.5194/angeo31-2229-2013, 2013.

Emmert, J., Picone, J., Lean, J., and Knowles, S.: Global change in the thermosphere: Compelling evidence of a secular decrease in density, J. Geophys. Res.-Space, 109, A02301, https://doi.org/10.1029/2003JA010176, 2004.

Emmert, J., Picone, J., and Meier, R.: Thermospheric global average density trends, 1967-2007, derived from orbits of 5000 near-Earth objects, Geophys. Res. Lett., 35, L05101, https://doi.org/10.1029/2007GL032809, 2008.

Emmert, J. T., Fejer, B. G., Shepherd, G. G., and Solheim, B. H.: Average nighttime $\mathrm{F}$ region disturbance neutral winds measured by UARS WINDII: Initial results, Geophys. Res. Lett., 31, L22807, https://doi.org/10.1029/2004GL021611, 2004.

Fejer, B., Blanc, M., and Richmond, A.: Post-Storm Middle and Low-Latitude Ionospheric Electric Fields Effects, Space Sci. Rev., 206, 407-429, 2017.

Fejer, B. G. and Emmert, J.: Low-latitude ionospheric disturbance electric field effects during the recovery phase of the 19-21 October 1998 magnetic storm, J. Geophys. Res.-Space, 108, 1454, https://doi.org/10.1029/2003JA010190, 2003.

Fuller-Rowell, T., Codrescu, M., Moffett, R., and Quegan, S.: Response of the thermosphere and ionosphere to geomagnetic storms, J. Geophys. Res.-Space, 99, 3893-3914, 1994.

Fuller-Rowell, T. J., Codrescu, M. V., Moffett, R. J., and Quegan, S.: Response of the thermosphere and ionosphere to geomagnetic storms, J. Geophys. Res., 99, 3893-3914, https://doi.org/10.1029/93JA02015, 1994.

Fuller-Rowell, T. J., Codrescu, M. V., Araujo-Pradere, E., and Kutiev, I.: Progress in developing a storm-time ionospheric correction model, Adv. Space Res., 22, 821-827, https://doi.org/10.1016/S0273-1177(98)00105-7, 1998.

Harding, B. J., Gehrels, T. W., and Makela, J. J.: Nonlinear regression method for estimating neutral wind and temperature from Fabry-Perot interferometer data, Appl. Opt., 53, 666-673, 2014.

International GPS Geodynamics Service (IGS): GPS data, available at: (ftp://data-out.unavco.org/pub/rinex/obs/, last access: 6 July 2018.

Kaab, M., Benkhaldoun, Z., Fisher, D. J., Harding, B., Bounhir, A., Makela, J. J., Laghriyeb, A., Malki, K., Daassou, A., and Lazrek, M.: Climatology of thermospheric neutral winds over Ouka"imeden Observatory in Morocco, Ann. Geophys., 35, 161170, https://doi.org/10.5194/angeo-35-161-2017, 2017.

Klobuchar, J. A.: Ionospheric effects on GPS, Global Positioning System: Theory and applications, 1, 485-515, 1996.

Lario, D., Kwon, R.-Y., Vourlidas, A., Raouafi, N. E., Haggerty, D. K., Ho, G. C., Anderson, B. J., Papaioannou, A., GómezHerrero, R., Dresing, N., and Riley, P.: Longitudinal Properties of a Widespread Solar Energetic Particle Event on 2014 February 25: Evolution of the Associated CME Shock, Astrophys. J., 819, 1-23, https://doi.org/10.3847/0004-637X/819/1/72, 2016.

Lee, C.-C., Liu, J.-Y., Reinisch, B. W., Lee, Y.-P., and Liu, L.: The propagation of traveling atmospheric disturbances observed during the April 6-7, 2000 ionospheric storm, Geophys. Res. Lett., 29, 1068, https://doi.org/10.1029/2001GL013516, 2002.
Lee, C.-C., Liu, J.-Y., Chen, M.-Q., Su, S.-Y., Yeh, H.-C., and Nozaki, K.: Observation and model comparisons of the traveling atmospheric disturbances over the Western Pacific region during the 6-7 April 2000 magnetic storm, J. Geophys. Res.-Space, 109, A09309, https://doi.org/10.1029/2003JA010267, 2004.

Makela, J. and Miller, E.: Optical observations of the growth and day-to-day variability of equatorial plasma bubbles, J. Geophys. Res.-Space, 113, A03307, https://doi.org/10.1029/2007JA012661, 2008.

Makela, J. J., Meriwether, J. W., Huang, Y., and Sherwood, P. J.: Simulation and analysis of a multi-order imaging Fabry-Perot interferometer for the study of thermospheric winds and temperatures, Appl. Opt., 50, 4403-4416, 2011.

Makela, J. J., Ridley, A., Hampton, D., Gerrard, A., Meriwether, J., Harding, B., Mesquita, R., Sanders, S., Castellez, M., Ciocca, M., Earle, G., and Frissell, N.: Observations of the storm time response of the mid-latitude thermosphere made by a network of Fabry-Perot interferometers, in: 40th COSPAR Scientific Assembly, 2-10 August 2014, Moscow, Russia, vol. 40 of COSPAR Meeting, 2014.

Mendillo, M.: Storms in the ionosphere: Patterns and processes for total electron content, Rev. Geophys., 44, RG4001, https://doi.org/10.1029/2005RG000193, 2006.

Meriwether, J.: Thermospheric Dynamics at Low and MidLatitudes During Magnetic Storm Activity, Midlatitude Ionospheric Dynamics and Disturbances, Geophys. Monogr. Ser., 181, Copyright 2008 by the American Geophysical Union. 201219, https://doi.org/10.1029/181GM19, 2008.

Ouattara, F. et al.: Variability of CODG TEC and IRI 2001 total electron content (TEC) during IHY campaign period (21 March to 16 April 2008) at Niamey under different geomagnetic activity conditions, Sci. Res. Essays, 6, 3609-3622, 2011.

Richmond, A.: Large-amplitude gravity wave energy production and dissipation in the thermosphere, J. Geophys. Res.-Space, 84, 1880-1890, 1979.

Richmond, A. and Matsushita, S.: Thermospheric response to a magnetic substorm, J. Geophys. Res., 80, 2839-2850, 1975.

Rishbeth, H. and Edwards, R.: The isobaric F2-layer, J. Atmos. Terr. Phys., 51, 321-338, 1989.

Sardon, E., Rius, A., and Zarraoa, N.: Estimation of the transmitter and receiver differential biases and the ionospheric total electron content from Global Positioning System observations, Radio Sci., 29, 577-586, 1994.

Schaer, S.: Mapping and predicting the Earth's ionosphere using the Global Positioning System., Geod.-Geophys. Arb. Schweiz, Zürich, Switzerland, 59, 1999.

Sethi, N., Pandey, V., and Mahajan, K.: Comparative study of TEC with IRI model for solar minimum period at low latitude, Advances in Space Research, 27, 45-48, 2001.

Singh, A., Rathore, V., Singh, R., and Singh, A.: Source identification of moderate $(-100 \mathrm{nT}<\mathrm{Dst}<-50 \mathrm{nT})$ and intense geomagnetic storms (Dst $<-100 \mathrm{nT}$ ) during ascending phase of solar cycle 24, Adv. Space Res., 59, 1209-1222, 2017.

Xiong, C., Lühr, H., and Fejer, B. G.: Global features of the disturbance winds during storm time deduced from CHAMP observations, J. Geophys. Res.-Space, 120, 5137-5150, https://doi.org/10.1002/2015JA021302, 2015.

Yashiro, S., Gopalswamy, N., Michalek, G., St Cyr, O., Plunkett, S., Rich, N., and Howard, R.: A catalog of white light coronal mass 
ejections observed by the SOHO spacecraft, J. Geophys. Res.Space, 109, A07105, https://doi.org/10.1029/2003JA010282, 2004.

Zhang, S.-R., Erickson, P. J., Foster, J. C., Holt, J. M., Coster, A. J., Makela, J. J., Noto, J., Meriwether, J. W., Harding, B. J., Riccobono, J., and Kerr, R. B.: Thermospheric poleward wind surge at midlatitudes during great storm intervals, Geophys. Res. Lett., 42, 5132-5140, 2015.
Zoundi, C., Ouattara, F., Fleury, R., Amory-Mazaudier, C., and Lassudrie-Duchesne, P.: Seasonal TEC variability in West Africa equatorial anomaly region, Eur. J. Sci. Res., 77, 309-319, 2012. 